\title{
OXYGEN CONSUMPTION IN DOGS AS INFLUENCED BY THE ALTERED METABOLISM OF DIABETES MELLITUS
}

\author{
By HAROLD G. DANFORD, ${ }^{1}$ ROBERT D. GALVIN, AND AKIRA HORITA \\ (From the Respiratory-Metabolic Section, Physiology Department, Army Medical Research \\ Laboratory, Fort Knox, Ky.)
}

(Submitted for publication December 12, 1955; accepted July 18, 1956)

The question of the total energy production in the human diabetic has been studied extensively by Benedict and Joslin $(1,2)$ and by Allen and $\mathrm{Du}$ Bois (3). It generally has been agreed that energy metabolism in mild cases of diabetes is normal, and that in the more severe cases is found increased when determined on the basis of kilogram of body weight. The lack of a satisfactory standard of comparison between diabetic and nondiabetic subjects hampered much of the earlier work in this field and led to disagreement regarding interpretation of data. Benedict and Joslin $(1,2)$, using the Harris-Benedict prediction standard, reported increases in metabolic rate of diabetic subjects of between 15 and 20 per cent. Lusk (4) criticized these data and computed that the increase in metabolism did not exceed 5 per cent. With the general acceptance of the more valid Du Bois standard (5) comprehending body surface area, many of the earlier data ascribing an increase in metabolic rate to diabetes have been recalculated and shown to be erroneous. More recent publications likewise have been of conflicting nature reporting increases in metabolic rate as great as 40 per cent and decreases of 32 per cent in severe clinical diabetes mellitus (6-9).

In the pancreatectomized dog, on the other hand, respiratory metabolism generally has been found to be increased (10-12). However, attempts at direct comparison between this type of acute canine diabetes and the disease as it occurs in humans is illogical in view of the typical alteration in fatty acid metabolism following pancreatectomy. We are not aware that oxidative metabolism has been measured previously in the alloxan diabetic animal which provides a metabolic defect more nearly identical with that occurring in human diabetes mellitus.

That an increase in oxygen consumption in dia-

\footnotetext{
${ }^{1}$ Present address: 733 13th Avenue, N.E., Rochester, Minnesota.
}

betes mellitus probably does not result from a uniform acceleration of metabolism of all body tissues, has been supported by the work of Kety, Polis, Nadler, and Schmidt (13) and Schecter, Wiesel, and Cohn (14) who demonstrated a decrease in oxygen utilization by the brain and extremities in patients with diabetic acidosis. In this report the basal total body oxygen consumption has been determined for the diabetic dog and a study made of its modification by insulin administration or hypophysectomy. Furthermore, the influence of experimental diabetes mellitus upon the hepatic blood flow and splanchnic oxygen consumption has been determined.

\section{MATERIAL AND METHODS}

Adult female dogs were used ranging in weight from 8 to $20 \mathrm{Kg}$. and housed indoors in a relatively constant environmental temperature of 24 to $26^{\circ} \mathrm{C}$. All animals were fed a fixed daily ration consisting of $10 \mathrm{gm}$. of Purina Laboratory Chow pellets and $10 \mathrm{gm}$. of horsemeat per kilogram. Five of the pancreatectomized animals received $100 \mathrm{gm}$. of fresh beef pancreas daily for 20-day periods which was substituted in the diet during that time for an equivalent quantity of horsemeat. Water was offered ad libitum.

The rate of oxygen consumption ${ }^{2}$ of the entire animal was obtained by an open circuit method previously described in detail (15) utilizing Liston-Becker and Beckman carbon dioxide and oxygen analyzers in the expiratory system to provide a constant index of the composition of the expired air. When the animal was in a basal state after a period of at least 30 minutes of complete rest, two successive samples of the dried expired air were drawn from the system in duplicate at an interval of 10 minutes and analyzed by the method described by Scholander (16). Provided the oxygen analyses of the two samples agreed within 0.05 per cent, the determination was believed to be reliable and oxygen consumption of the dog was calculated. The data have been converted to their respective values for standard conditions of temperature and barometric pressure.

\footnotetext{
2 The oxygen consumption apparatus was designed and constructed by Captain F. A. Miller.
} 
All determinations of oxygen consumption were carried out on the trained unanesthetized animal excepting those done in conjunction with the estimation of hepatic blood flow and splanchnic oxygen consumption. These latter experimental procedures were performed under sodium pentobarbital anesthesia. Care was taken with the training of the unanesthetized dogs in order to ensure the maintenance of a basal condition. All animals were studied 24 hours after the last ingestion of food and at complete rest, being devoid of all voluntary or extraneous involuntary movement. Individual animals were studied repeatedly under control and experimental conditions until a plateau level for oxygen consumption was reached which could be reproduced from day to day. Under these circumstances the lowest rates of oxygen utilization were incorporated into the data. Basal oxygen consumption determinations in the pancreatectomized dogs were not believed to be totally reliable until after the incision was well healed, a period of approximately two weeks. Rectal temperature for each dog was measured immediately following an oxygen consumption determination. Only animals whose temperature fell within the range $38 \pm 0.5^{\circ} \mathrm{C}$ were acceptable for this series. The basal per $\mathrm{kg}$. oxygen consumptions of 51 well trained normal dogs determined by this procedure have been found to be in good general agreement with similarly acquired values obtained by other laboratories (17).

The bromsulphthalein (BSP) extraction method for the estimation of hepatic blood flow as described by Bradley, Ingelfinger, Bradley, and Curry (18) was applied to dogs in order to provide a means whereby the splanchnic oxygen consumption might be determined in diabetes mellitus. This technique has been compared in the dog with simultaneous direct measurement of hepatic blood flow by Selkurt (19) who reports values for the BSP method exceeding direct measurement by approximately 7 per cent. This difference is thought to be due to a small extrahepatic loss of the dye. Under sodium pentobarbital anesthesia ( $25 \mathrm{mg}$. per $\mathrm{Kg}$.) and using fluoroscopic control a number 6 or 8 Cournand type cardiac catheter was inserted via the external jugular vein into a large hepatic vein in either the right or left lobe of the liver. Indwelling polyethylene cannulae were inserted high into the external saphenous vein and into the right atrium through the external jugular vein. After a priming dose of 50 to $100 \mathrm{mg}$. of BSP, an infusion of approximately $2.0 \mathrm{mg}$. BSP in isotonic saline per minute was delivered through the intra-atrial cannula by a calibrated constant infusion apparatus. A slow infusion of isotonic sodium chloride was passed through the hepatic and saphenous cannulae to maintain their patency when not in use. Following a 30-minute period to allow for stabilization of the peripheral BSP level, three pairs of blood samples were drawn at 10-minute intervals simultaneously from the hepatic and saphenous veins for BSP analysis. Hepatic venous and femoral arterial bloods for determination of oxygen content were obtained just prior to the second BSP sampling. Plasma BSP levels were measured colorimetrically as described by Myers (20) and blood oxygen content was measured by the manometric method of Peters and Van Slyke (21). Hepatic blood flow was calculated as outlined by Bradley, Ingelfinger, Bradley, and Curry (18) and the splanchnic oxygen consumption was derived from the product of the hepatic blood flow and the arterial-hepatic venous oxygen difference. The maximum observed rate of change in concentration of the peripheral BSP was $.0005 \mathrm{mg}$. per $\mathrm{ml}$. per minute. The total blood volume was assumed to be $100 \mathrm{ml}$. per $\mathrm{Kg}$. of body weight, this value was derived from the data of Krieger, Storaasli, Friedell, and Holden (22). All experiments were carried out at $38 \pm$ $0.5^{\circ} \mathrm{C}$ body temperature.

The subtemporal intracranial approach was utilized for hypophysectomy as has been described previously by Keller, Lawrence, and Blair (23). Pancreatectomy was performed through a longitudinal mid-line incision, taking care to remove all pancreatic tissue. Alloxan diabetes was induced by the rapid intravenous administration of 75 to $100 \mathrm{mg}$. per Kg. of alloxan. Phlorhizin diabetes was produced in the fasted dog by the subcutaneous administration of $2 \mathrm{gm}$. of phlorhizin suspended in olive oil on two successive days with the chemical and metabolic determinations in these animals being made 24 hours following the last dose of the drug. Recovery from

TABLE I

INFLUENCE OF ACIDOSIS, KETOSIS AND DIABETES MELLITUS UPON OXYGEN CONSUMPTION IN DOGS

\begin{tabular}{|c|c|c|c|c|c|c|c|c|c|}
\hline & $\begin{array}{c}\text { NUMBER } \\
\text { OF } \\
\text { DOGS } \\
\end{array}$ & $\begin{array}{c}\text { WEIGHT } \\
\text { Kg. }\end{array}$ & \begin{tabular}{|l|} 
OXYGEN \\
CONSUMPTION \\
$\mathrm{ml} / \mathrm{kg} . / \mathrm{min}$. \\
\end{tabular} & RQ & $\begin{array}{l}\text { BLOOD SUGAR } \\
\mathrm{mg} . / 100 \mathrm{ml} .\end{array}$ & $\begin{array}{c}\text { BLOOD ACE TONE } \\
\mathrm{mg} . / 100 \mathrm{mI} \text {. }\end{array}$ & $\begin{array}{c}\text { BLOOD TOTAL } \\
\text { KETONE } \\
\mathrm{mg} .1100 \mathrm{ml} . \\
\end{array}$ & PH & $\begin{array}{c}\text { PLASMA } \mathrm{CO}_{2} \\
\text { CONTENT } \\
\text { mEQ./L. } \\
\end{array}$ \\
\hline CONTROL & 6 & $11.4 \pm 1.0+$ & $5.89 \pm .65$ & $.75 \pm .10$ & $82 \pm 10$ & $0.9 \pm 0.3$ & $2.2 \pm 0.8$ & $7.36 \pm .02$ & $23.6 \pm 1.4$ \\
\hline ACIDOSIS & 6 & $11.3 \pm 1.1$ & $5.96 \pm .95$ & $.73 \pm .04$ & $85 \pm 9$ & $1.0 \pm 0.4$ & $1.6 \pm 0.5$ & $7.10 \pm .04^{*}$ & $9.9 \pm 2.1$ * \\
\hline FASTING & 6 & $10.1 \pm 1.0 *$ & $5.87 \pm .40$ & $.64 \pm .09$ & $65 \pm 9^{*}$ & $1.9 \pm 0.2$ & $4.6 \pm 1.7 *$ & $7.32 \pm .06$ & $22.7 \pm 2.4$ \\
\hline $\begin{array}{l}\text { PHLORHIZIN } \\
\text { OIABETES }\end{array}$ & 6 & $9.9 \pm 1.1^{*}$ & $7.66 \pm .74 *$ & $.70 \pm .04$ & $41 \pm 8^{*}$ & $11.5 \pm 2.8^{*}$ & $20.9 \pm 7.7^{*}$ & $7.22 \pm .10^{*}$ & $16.8 \pm 2.4^{*}$ \\
\hline $\begin{array}{l}\text { ALLOXAN } \\
\text { DIABETES }\end{array}$ & 3 & $9.5 \pm 0.4^{*}$ & $7.82 \pm .57^{*}$ & $.68 \pm .02$ & $635 \pm 187^{*}$ & $3.1 \pm 1.6^{*}$ & $5.5 \pm 2.4$ & $7.22 \pm .04^{*}$ & $17.2 \pm 2.4^{*}$ \\
\hline $\begin{array}{l}\text { PANCREATEC- } \\
\text { TOMY DIA- } \\
\text { BETES }\end{array}$ & 3 & $9.3 \pm 0.4^{*}$ & $8.86 \pm .08 *$ & $.66 \pm .03$ & $228 \pm 53^{*}$ & $9.7 \pm 3.0^{*}$ & $22.7 \pm 6.9^{*}$ & $7.19 \pm .05 *$ & $18.7 \pm 3.4^{\prime \prime}$ \\
\hline
\end{tabular}

+ MEAN \pm STANDARD DEVIATION.

- DENOTES A SIGNIFICANT DIFFERENCE FROM THE MEAN OF THE CONTROL SERIES AT THE P <. OS LEVEL, FROM FISHER'S TABLE OF T VALUES. 
TABLE II

INFLUENCE OF INSULIN UPON THE OXYGEN CONSUMPTION OF ALLOXAN AND PANCREATECTOMIZED DAAETIC DOGS

\begin{tabular}{|c|c|c|c|c|c|c|c|c|c|c|c|}
\hline & & $\begin{array}{c}\text { OXYEEN } \\
\text { Consumption } \\
\text { ml./Ko/min. }\end{array}$ & ne & $\begin{array}{c}\text { DLOOD } \\
\text { sucAR } \\
\text { me./100ml. }\end{array}$ & $\begin{array}{c}\text { URINE } \\
\text { SUGAR } \\
\text { om./Ko./doy }\end{array}$ & 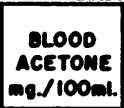 & \begin{tabular}{|c|} 
OLOOD \\
RETONE \\
BOOHES \\
Ge/loOnd.
\end{tabular} & DH & $\begin{array}{l}\text { PLASMACO } \\
\text { CONTENT } \\
\text { mEq/IItOT }\end{array}$ & $\begin{array}{c}\text { WEISHT } \\
\text { KILOGRAMS }\end{array}$ & $\begin{array}{l}\text { PROTAMINE } \\
\text { ZN INSULIN } \\
\text { unlts/doy }\end{array}$ \\
\hline $\begin{array}{l}\text { UNCON- } \\
\text { TROLLEO } \\
\text { OIABETES }\end{array}$ & $\begin{array}{l}\text { PANCREAT- } \\
\text { ECTOMY } \\
\text { ALLOXAN }\end{array}$ & $\begin{array}{c}8.65^{+} \\
(8.03-8.98)^{\circ} \\
\\
7.72 \\
(7.37-8.22)\end{array}$ & $\mid \begin{array}{c}.68 \\
(.62-.08)\end{array}$ & $\begin{array}{c}192 \\
(142-281)\end{array}$ & $\begin{array}{c}8.39 \\
(4.26-6.051\end{array}$ & $\begin{array}{c}1.7 \\
(0.9-2.7)\end{array}$ & $\begin{array}{c}4.5 \\
(2.2-7.6)\end{array}$ & $\begin{array}{c}7.32 \\
(7.26-7.38)\end{array}$ & $\begin{array}{c}23.0 \\
(22.2-24.6)\end{array}$ & $\begin{array}{l}10.8 \\
(9.0-14.1)\end{array}$ & $\begin{array}{l}0 \\
0\end{array}$ \\
\hline $\begin{array}{l}\text { INSULIN } \\
\text { CON- } \\
\text { TROLLED } \\
\text { DIABETES }\end{array}$ & $\begin{array}{l}\text { PANCREAT- } \\
\text { ECTONY } \\
\text { ALLOXAN }\end{array}$ & $\frac{5.82}{\left(5.32^{-6.39)}\right.}$ & $\begin{array}{c}.70 \\
(.68-.73)\end{array}$ & $\begin{array}{c}74 \\
(37-128)\end{array}$ & $\begin{array}{c}1.39 \\
(.33-2.71)\end{array}$ & $\left(0.9^{1.2}-1.6\right)$ & $\begin{array}{c}3.0 \\
(3.4-4.0)\end{array}$ & $\begin{array}{c}7.37 \\
(7.38-7.38)\end{array}$ & $\mid \begin{array}{c}21.7 \\
(20.9-22.3)\end{array}$ & $\frac{11.1}{(9.0-14.4)}$ & $\stackrel{9}{(7-10)}$ \\
\hline
\end{tabular}

+ MEAN

- RANGe

the effects of phlorhizin was considered complete with return of the fasting blood sugar to the range of 70 to 90 $\mathrm{mg}$. per $100 \mathrm{ml}$. and the disappearance of glucosuria. Further use of phlorhizin poisoned animals was delayed until these criteria were satisfied. In view of the increased susceptibility of the diabetic dog to infection, sufficient penicillin was administered during the course of the experiment to prevent the development of any septic condition. At termination the brain in the hypophysectomized dogs was removed with the fossal scar remaining undisturbed and still attached to the ventral part of the hypothalamus. After fixation in Bouin's solution, the blocks of the hypophysis-hypothalamus were sectioned sagittally and serially. Appropriate sections were mounted and stained by Maximow, Pal-Weigert, Mallory, and Heidenhain procedures. The anatomical degree of hypophysectomy was estimated from the histological sections and classified as defined by Keller, Lawrence, and Blair (23).

Fasting blood sugar, 24-hour urine sugar output, arterial acetone and total ketone bodies (24), arterial pH and arterial plasma carbon dioxide content determinations were performed immediately following oxygen consumption procedures. The analysis of total liver lipids was carried out on both biopsy and autopsy liver specimens as described by Kaplan and Chaikoff (25). Biopsy wedges of liver tissue weighing approximately $3 \mathrm{gm}$. were obtained under general anesthesia the day following oxygen consumption determinations. Insulin tolerance to a given dose of crystalline insulin was ascertained for each hypophysectomized dog prior to pancreatectomy to serve as a physiological index of the completeness of hypophysectomy as reflected by the extent of the available carbohydrate reserve (23).

\section{RESULTS}

The data comprising Table I show that acidosis resulting from the ingestion of ammonium chloride ( $0.4 \mathrm{gm}$. per $\mathrm{Kg}$. three times daily for two days) did not alter materially the oxygen consumption of 6 dogs from that of the control period. The mean arterial $\mathrm{pH}$ of 7.10 and carbon dioxide content in the plasma of $9.9 \mathrm{mEq}$. per liter indicate an acidosis of comparable degree to that of diabetic acidosis. It is shown also that a fasting period of 10 days with a resultant average weight loss of 11 per cent produced no change in oxygen consumption. In contrast to the lack of effect of these two factors, the injection of phlorhizin into each of the 6 dogs, while maintained under fasting conditions, caused an increased oxygen utilization exceeding 20 per cent in 5 of the 6 animals. This observation has been reported by Lusk (26) and confirmed by Boothby, Wilhelmj, and Wilson (27), although its mechanism has not been determined. In 3 dogs the basal oxygen consumption following establishment of the diabetes by pancreatectomy exceeded the control for these animals by approximately 45 per cent. Of the 3 alloxan diabetic dogs, all exhibited increases in metabolic rate following the production of the diabetes. One of the 3 dogs' metabolic rate was elevated to the same general degree as that of the pancreatectomized dogs; in the remaining 2 the increases were 18 and 29 per 


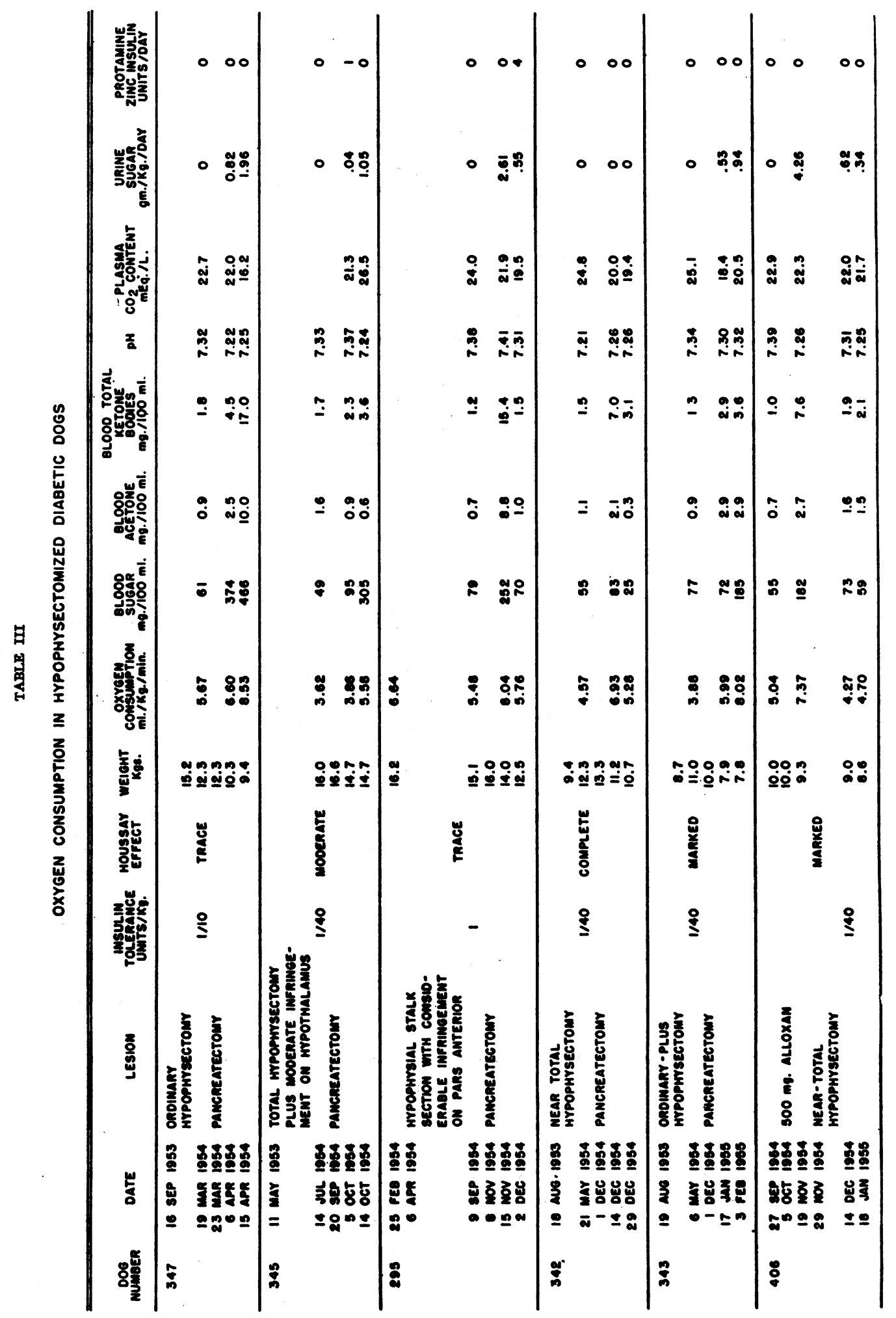


cent. At no time during the diabetic period did the oxygen consumption approach control levels in any animal provided insulin was withheld and the diabetes went uncontrolled.

Since increased rates of oxygen consumption generally were measured in association with elevated ketone body concentrations of the peripheral blood, the blood ketone concentration was artificially elevated in two normal dogs. Acetone and beta-hydroxybutyric acid were injected intravenously using $90 \mathrm{gm}$. of acetone and $150 \mathrm{mg}$. of beta-hydroxybutyric acid per kilogram of body weight to produce in one hour after administration elevations in circulating ketone bodies of the magnitude found in diabetic acidosis. At that time the rate of oxygen consumption was found to be normal; this tended to eliminate the presence of ketonemia per se as cause for the previously observed elevated rates of oxygen consumption in diabetes mellitus.

The influence of protamine zinc insulin upon the oxygen consumption and carbohydrate metabolism in alloxan and pancreatectomized diabetic dogs is demonstrated by the data in Table II. The insulin requirement for suppression of glucosuria, maintenance of the fasting blood sugar at about $100 \mathrm{mg}$. per $100 \mathrm{ml}$., and prevention of the acidosis and ketonemia was similar for both groups. The data of Table II express the arithmetic mean and the range of values obtained for the 3 dogs comprising each group prior to and following insulin administration. The oxygen utilization, during treatment with insulin, uniformly decreased in all of the dogs, although the magnitude of reduction was only 10 per cent in the pancreatectomized animals whereas it reverted to control levels in dogs made diabetic with alloxan. The data indicate that the increased oxygen consumption observed in the pancreatectomized dog is brought about by multiple factors, only one of which is the absence of insulin. That incident to alloxan diabetes apparently results solely from insulin deficiency.

In Table III the data illustrate how the amelioration of diabetes mellitus by hypophysectomy influences the rate of oxygen consumption. As will be noted from the Table the anatomical degree of hypophysectomy varied from animal to animal as did their carbohydrate reserve as measured by the insulin tolerance. The magnitude of the ensuing Houssay effect likewise was found to be variable.

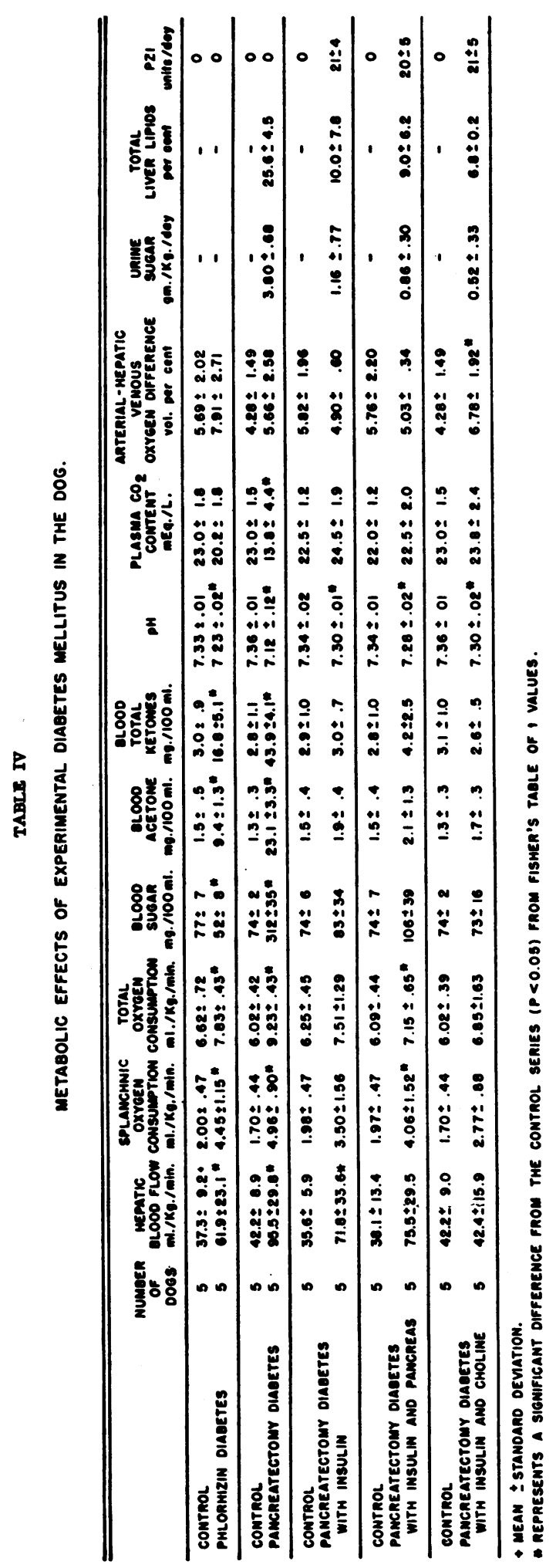


Nevertheless, all 6 pancreatized hypophysectomized animals exhibited an attenuated diabetes mellitus (Houssay effect) as evidenced by a relatively mild hyperglycemia, glucosuria, ketosis, acidosis and intermittent spontaneous episodes of hypoglycemia. The rate of oxygen consumption of the Houssay dog varied considerably from day to day. The lower rates coincided with periods of remission of the diabetes and did not exceed those of the normal dog, whereas maximal rates of oxygen consumption were associated with periods of exacerbation of the diabetes and approached or exceeded $8.0 \mathrm{ml}$. per kilogram per minute in 3 of the experimental animals. The mean hepatic lipid of the 6 Houssay dogs as analyzed chemically at termination was 11.9 per cent. This figure represents a mild fatty infiltration of the liver in contrast to the 30 to 50 per cent lipid level reported following pancreatectomy (25).

The determination of the splanchnic bed oxygen uptakes for groups of 5 pancreatectomized dogs and their rates of total body oxygen consumption appear in Table IV. These data are compared with control measurements prior to diabetes. Phlorhizin diabetes or simple pancreatectomy diabetes results in significantly increased rates of total body oxygen consumption, hepatic blood flow and splanchnic oxygen consumption. Whereas under control conditions the mean splanchnic oxygen uptake represented approximately 30 per cent of the total body oxygen consumption, this ratio exceeded 50 per cent following injection of phlorhizin or pancreatectomy. This disproportionate increase in rate of liver metabolism in diabetes mellitus was of sufficient magnitude to account for the absolute elevation measured in total oxygen utilization. The administration of insulin to pancreatectomized dogs for periods of 3 weeks, either alone or in combination with lipotropically active substances by mouth (fresh beef pancreas $100 \mathrm{gm}$. per day or choline chloride $2 \mathrm{gm}$. per day) was found to prevent a measurable increase in oxygen utilization in approximately 40 per cent of the animals. The combination of insulin with choline was found to be most efficacious in this respect since the mean rate of hepatic blood flow was unchanged and increases in oxygen consumption were small and insignificant in choline fed dogs following pancreatectomy. The lipid content of liver biopsies could not be correlated with the rate of splanchnic oxygen consumption. Massive infiltration of the liver with fat, however, was associated with consistently elevated rates of splanchnic bed metabolism, but similar increases frequently were observed with only minor increments in the level of total liver lipids.

\section{DISCUSSION}

In view of the importance of fatty acids as an energy source in uncontrolled diabetes mellitus, their incomplete oxidation and excretion in the urine as ketone bodies might be expected to result in a poor economy of combustion leading to an increased oxygen utilization under "basal" conditions. Since the partial preliminary oxidation of fats is primarily a function of the liver, attention has been focused upon this organ as a possible site of increased metabolic activity in diabetes mellitus which might be in large part responsible for the measured increase in total body oxygen consumption. Therefore the splanchnic oxygen uptake in the diabetic dog has been determined and used as a measure of rate of liver metabolism.

The foregoing experimental procedures have indicated that the metabolic condition giving rise to a state of ketosis whether resulting from diabetes mellitus of phlorhizin, alloxan, or pancreatectomy etiology nearly always is accompanied by increased rates of oxygen consumption. The usual reduction in respiratory quotient accompanying diabetes mellitus necessarily would reduce the caloric equivalent for utilized oxygen to a slight degree ( 3 per cent) in certain of the diabetic preparations. However, the observed changes when present were of such magnitude as to eliminate this as a factor of importance. The administration of insulin to or hypophysectomy of the diabetic dog have been found to reduce elevated ketone body concentrations to approximately normal levels while tending to produce a lability in the elevated total body oxygen utilization from day to day that cannot be correlated always with minor fluctuations in the chemical analyses of blood or urine.

The possibility that one of the manifestations of the fatty liver secondary to deficiency of pancreatic lipotropic substance might be an elevated rate of oxygen consumption was suggested by the recent publication of Kessler, Liebler, Bronfin, 
and Sass (28) who demonstrated elevated splanchnic and total oxygen consumptions resulting from fatty infiltration of the liver in alcoholic patients. The two lipotropic agents used in this investigation were administered to dogs in the dosage found effective in preventing fatty infiltration of the liver by Prohaska, Dragstedt, and Harms (29). Unfortunately no distinct relationship was found to exist between oxygen consumption and the fat content of the liver since values of the former frequently were elevated without appreciable liver fat being present. However, massive infiltration of the liver with fat invariably was associated with considerable elevation in rate of oxygen consumption. These findings are in general agreement with those of Bogoch, Casselman, Kaplan, and Bockus (30) who after meticulous clinical study of hepatic function in diabetes mellitus conclude that "no correlation could be established between the degree of fatty metamorphosis of the liver and any other histochemical or laboratory observation."

\section{CONCLUSIONS}

Total body oxygen consumption persistently increased from 20 to 50 per cent in the presence of the diabetes mellitus induced in dogs by phlorhizin, alloxan or pancreatectomy; the magnitude of the increase was associated with the severity of the diabetes. Insulin control of alloxan diabetes returned oxygen consumption to the normal range. Insulin control of the diabetes following pancreatectomy regularly decreased total oxygen consumption but did not, except on occasion, lower it to the prediabetic level regardless of whether choline or beef pancreas was supplied.

Hypophysectomized pancreatectomized dogs manifest a mild but labile diabetes mellitus with little tendency for development of ketosis or fat accumulation in the liver. Minimal rates of oxygen utilization in a series of Houssay animals were obtained while the diabetes had undergone a spontaneous remission and did not exceed rates for normal dogs under basal conditions. Periods of diabetic exacerbation were characterized by elevated rates of oxygen consumption.

The mean absolute increase in splanchnic oxygen uptake in a series of pancreatectomized dogs was found to equal or exceed simultaneously measured increases in the total oxygen consumption and thus roughly account for the elevated rate in total metabolism. Insulin in combination with choline was found slightly more effective than insulin with beef pancreas or insulin alone in its ability to restore elevated rates of oxygen consumption to normal in pancreatectomized dogs. No direct correlation was drawn between the total lipid content of the liver and the splanchnic oxygen consumption except that massive fatty infiltration of the liver was accompanied by maximal elevations in splanchnic and total oxygen utilization.

\section{ACKNOWLEDGMENT}

The authors wish to acknowledge the assistance of Doctor A. D. Keller for the surgical preparation of animals used in this report.

\section{REFERENCES}

1. Benedict, F. G., and Joslin, E. P., Metabolism in diabetes mellitus. Washington, Carnegie Institute of Washington, 1910 (Publication No. 136).

2. Benedict, F. G., and Joslin, E. P., A study of metabolism in severe diabetes. Washington, Carnegie Institute of Washington, 1912. (Publication No. 176).

3. Allen, F. M., and Du Bois, E. F., Clinical calorimetry. Seventeenth paper. Metabolism and treatment in diabetes. Arch. Int. Med., 1916, 17, 1010.

4. Lusk, G., Book review of Benedict and Joslin, Metabolism in diabetes mellitus. Science, 1911, 33, 433.

5. Du Bois, D., and Du Bois, E. F., A formula to estimate the approximate surface area if height and weight be known. Arch. Int. Med., 1916, 17, 863.

6. Wilder, R. M., Boothby, W. M., and Beeler, C., Studies of the metabolism of diabetes. J. Biol. Chem., 1922, 51, 311.

7. Holten, C., The respiratory metabolism in diabetics and the influence of insulin upon it. J. Metab. Research, 1924, 6, 1.

8. Horstmann, P., The oxygen consumption in diabetes mellitus. Acta med. Scandinav., 1951, 139, 326.

9. Fisher, P., and Kleinerman, J. I., Total oxygen consumption and metabolic rate of patients in diabetic acidosis. J. Clin. Invest., 1952, 31, 126.

10. Hédon, L., Le quotient respiratoire et le métabolisme de base dans le diabète pancréatique expérimental. ( $3^{\mathrm{m} \bullet}$ mémoire) Arch. internat. de physiol., 1927, 29, 175.

11. Falta, W., Grote, F., and Staehelin, R., Versuche über Stoff wechsel und Energieverbrauch an pankreaslosen Hunden. Beitr. z. chem. Physiol. u. Path., 1907, 10, 199.

12. Murlin, J. R., and Kramer, B., The influence of pancreatic and duodenal extracts on the glucosuria and respiratory metabolism of depancreatized dogs. J. Biol. Chem., 1913, 15, 365. 
13. Kety, S. S., Polis, B. D., Nadler, C. S., and Schmidt, C. F., The blood flow and oxygen consumption of the human brain in diabetic acidosis and coma. J. Clin. Invest., 1948, 27, 500.

14. Schecter, A. E., Wiesel, B. H., and Cohn, C., Peripheral circulatory failure in diabetic acidosis and its relation to treatment. Am. J. M. Sc., 1941, 202, 364.

15. Danford, H. G., and Galvin, R. D., Oxygen consumption in dogs as influenced by the altered metabolism of diabetes mellitus. Army Medical Research Laboratory Report No. 210, 1955.

16. Scholander, P. F., Analyzer for accurate estimation of respiratory gases in one-half cubic centimeter samples. J. Biol. Chem., 1947, 167, 235.

17. Kunde, M. M., and Steinhaus, A. H., Studies on metabolism. IV. The basal metabolic rate of normal dogs. Am. J. Physiol., 1926, 78, 127.

18. Bradley, S. E., Ingelfinger, F. J., Bradley, G. P., and Curry, J. J., The estimation of hepatic blood flow in man. J. Clin. Invest., 1945, 24, 890.

19. Selkurt, E. E., Comparison of the bromsulphalein method with simultaneous direct hepatic blood flow. Circulation Research, 1954, 2, 155.

20. Myers, J. D., The hepatic blood flow and splanchnic oxygen consumption of man-their estimation from urea production or bromsulphalein excretion during catheterization of the hepatic veins. J. Clin. Invest., 1947, 26, 1130.

21. Peters, J. P., and Van Slyke, D. D., Quantitative Clinical Chemistry. Vol. II. Methods. Baltimore, Williams and Wilkins, 1932.

22. Krieger, H., Storaasli, J. P., Friedell, H. L., and
Holden, W. D., A comparative study of blood volume in dogs. Proc. Soc. Exper. Biol. \& Med., 1948, 68, 511.

23. Keller, A. D., Lawrence, W. E., and Blair, C. B., Effects of varying degrees of hypophysectomy in the dog. Arch. Path., 1945, 40, 289.

24. Greenberg, L. A., and Lester, D., A micromethod for the determination of acetone and ketone bodies. J. Biol. Chem., 1944, 154, 177.

25. Kaplan, A., and Chaikoff, I. L., Liver lipids in completely depancreatized dogs maintained with insulin. J. Biol. Chem., 1935, 108, 201.

26. Lusk, G., The Elements of the Science of Nutrition. Fourth edition, Philadelphia and London, Saunders, 1928.

27. Boothby, W. M., Wilhelmj, C. M., and Wilson, H. E. C., The question of the oxidation of glucose in phlorhizin glucosuria. J. Biol. Chem., 1929, 83, 657.

28. Kessler, B. J., Liebler, J. B., Bronfin, G. J., and Sass, M., The hepatic blood flow and splanchnic oxygen consumption in alcoholic fatty liver. J. Clin. Invest., 1954, 33, 1338.

29. Prohaska, J. V., Dragstedt, L. R., and Harms, H. P., The relation of pancreatic juice to the fatty infiltration and degeneration of the liver in the depancreatized dog. Am. J. Physiol., 1936, 117, 166.

30. Bogoch, A., Casselman, W. G. B., Kaplan, A., and Bockus, H. L., Studies of hepatic function in diabetes mellitus, portal cirrhosis and other liver diseases. A correlation of clinical, biochemical and liver needle biopsy findings. I. Diabetes mellitus. Am. J. Med., 1955, 18, 354. 